\section{Eosinophilic Fasciitis in Association With Hypereosinophilic Syndrome in an HIV-Infected Patient With Severe Multiorgan Involvement}

Richarz NA ${ }^{1}$, Olivé Marques $\mathrm{A}^{2}$, Llibre $\mathrm{JM}^{3}$, Xicoy Cirici $\mathrm{B}^{4}$, Zhu N ${ }^{5}$, Gomez Plaza $\mathrm{M}^{6}$, Bielsa-Marsol I ${ }^{1}$

${ }^{1}$ Department of Dermatology, Hospital Universitari Germans Trias i Pujol, Badalona, Universitat Autònoma de Barcelona, Spain

${ }^{2}$ Department of Rheumatology, Hospital Universitari Germans Trias i Pujol, Badalona, Universitat Autònoma de Barcelona, Spain

${ }^{3}$ Department of Internal Medicine, Hospital Universitari Germans Trias i Pujol, Badalona, Universitat Autònoma de Barcelona, Spain ${ }^{4}$ Department of Hematology, Institut Català d'Oncologia, Badalona, Josep Carreras Leukemia Research Institute, Universitat Autònoma de Barcelona, Spain

${ }^{5}$ Department of Neurology, Hospital Universitari Germans Trias I Pujol, Universitat Autònoma de Barcelona, Spain

${ }^{6}$ Department of Pathology, Hospital Universitari Germans Trias i Pujol, Badalona, Universitat Autònoma de Barcelona, Spain

J Investig Allergol Clin Immunol 2018; Vol. 28(2): 126-128 doi: 10.18176/jiaci.0216

Key words: Eosinophilic fasciitis. Hypereosinophilic syndrome. Cytokine storm. Reactive hypereosinophilia. Cerebral border zone ischemia.

Palabras clave: Fascitis eosinofílica. Síndrome hipereosinofílico. Tormenta de citoquinas. Hipereosinofilia reactiva. Isquemia cerebral en territorio frontera.

Eosinophilic fasciitis (EF) is a rare inflammatory disorder of the fascia and subcutaneous tissue characterized by painful swelling with progressive induration and thickening of the skin and underlying tissue. Reactive nonclonal hypereosinophilia in bone marrow biopsy with peripheral hypereosinophilia can be observed in $63 \%-93 \%$ of cases, although it does not confirm the diagnosis $[1,2]$. Visceral involvement due to hypereosinophilia in $\mathrm{EF}$ is very unusual and needs to be differentiated from other conditions causing hypereosinophilia with organ involvement (systemic sclerosis, toxic oil syndrome, eosinophilia-myalgia syndrome, eosinophilic granulomatosis with polyangiitis [Churg-Strauss syndrome], neoplastic hypereosinophilic syndrome, drug-induced hypereosinophilic syndrome, and infectious diseases). We report a case of EF in an HIV-1-positive patient with no AIDS-defining conditions who experienced life-threatening secondary multiorgan involvement due to persistent hypereosinophilia over $>1$ month that responded to immunosuppressive therapy.
A 50-year-old woman with HIV-1 infection diagnosed in 2009 and taking regular antiretroviral treatment (emtricitabine, tenofovir, rilpivirine) with suppression of plasma HIV-1 RNA $(<50$ copies $/ \mathrm{mL})$ and a $\mathrm{CD}^{+}$lymphocyte count of 242 cells $/ \mathrm{mm}^{3}$ consulted for bilateral pitting edema with symmetric skin thickening on both forearms and legs that had developed progressively over the previous 2 months. She also reported watery stool twice daily for the previous 3 months with no significant weight loss. Laboratory results showed repeatedly high levels of blood eosinophilia $\left(1.52 \times 10^{9} / \mathrm{L}, 19 \%\right)$, with a normal white blood cell count $\left(8 \times 10^{9} / \mathrm{L}\right)$, normocytic normochromic anemia $(\mathrm{Hb}, 9.7 \mathrm{~g} / \mathrm{dL})$, and severe hypoalbuminemia $(26.6 \mathrm{~g} / \mathrm{L})$. Stool tests ruled out a parasitic or opportunistic infection. Repeated questioning did not reveal drug intake other than that previously reported. In addition, a blood test revealed negative antinuclear antibodies and antineutrophil cytoplasmic antibodies with normal IgE, lactate dehydrogenase, complement $\mathrm{C} 3$ and $\mathrm{C} 4$, creatine kinase, and aldolase. Findings for tumor markers were within the reference ranges. A deep skin biopsy of her upper right thigh revealed findings compatible with EF (Figure, A). Computed tomography of the abdomen revealed mild wall thickening in the distal ileum and rectum, with no significant abnormalities on gastroscopy or colonoscopy. Eosinophilic gastroenteritis was suspected but could not be confirmed by normal superficial endoscopic duodenal biopsy. Associated myeloid or lymphoid malignancies were

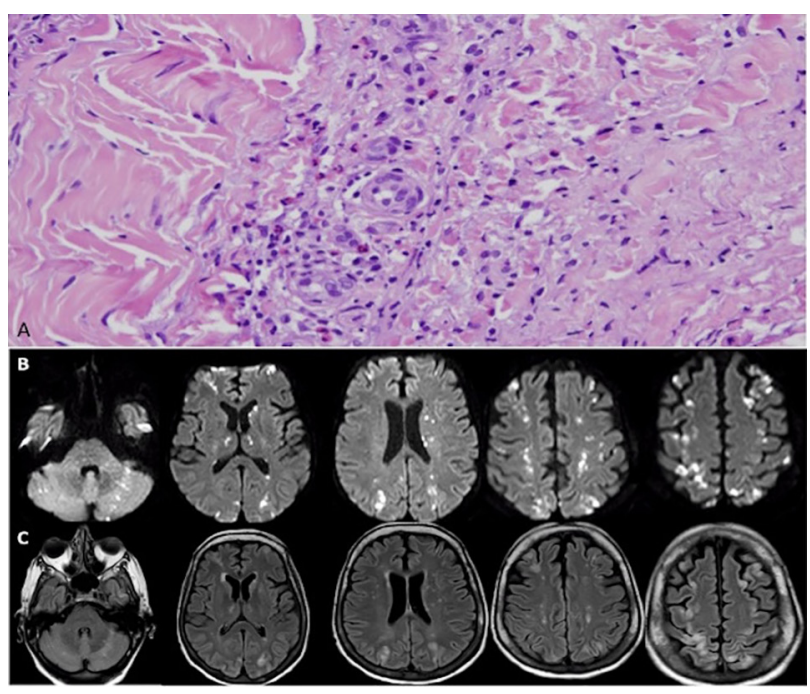

Figure. A, Hematoxylin-eosin. Dense infiltration of eosinophils and lymphocytes extending from the dermis to the fascia with signs of dermal fibrosis but no granulomas or vasculitis. B and C, Diffusion-weighted (B) and FLAIR $(C)$ magnetic resonance images showing multiple small acute ischemic lesions in internal border zone (bilateral) and the cerebral cortices, the thalamus and cerebellum (bilateral), and the left caudate nucleus. 
excluded based on peripheral blood morphology (no myeloid precursors in peripheral blood and no dysplasia) and bone marrow studies showing a reactive eosinophilic infiltrate $(24 \%)$ in all maturative states, normal karyotype, and absence of genetic abnormalities (BCR/ABL1, FIP1L1-PDGFRA, ETV6/RUNX1, FGR1, and T-cell receptor gamma) by FISH/ PCR studies. During hospitalization, the patient developed peripheral neurological symptoms compatible with asymmetric sensory multiple mononeuropathy with axonal damage, as seen using electromyography. The patient's condition deteriorated further and she presented disorientation, somnolence with dysphagia, and progressive flaccid tetraparesis. Cerebral MRI revealed multiple small lesions in internal border zones (bilateral), the cerebral cortices, the thalamus and cerebellum (bilateral), and the left caudate nucleus (Figure, B and C). The results of complete brain arteriography and echocardiography were normal, with no endocardial vegetations or intracavitary thrombi. Eosinophilic vascular infiltration and toxicity were suspected of being responsible for the peripheral axonal damage and the multiple cerebral ischemic lesions. Pulmonary symptoms with dry cough, fever, and changing pulmonary infiltrates on the chest radiograph without leukocytosis were interpreted as pulmonary manifestations of the same disease, after ruling out all infectious causes. Subsequently, immunosuppressive therapy based on intravenous bolus of methylprednisolone $(1000 \mathrm{mg} / \mathrm{d} \times 3$ days $)$ was initiated and then tapered to $1.5 \mathrm{mg} / \mathrm{kg} / \mathrm{d}$, combined with a monthly bolus of cyclophosphamide $\left(365 \mathrm{mg} / \mathrm{m}^{2}\right)$. The patient gradually recovered (symptoms and radiological evidence), with normalization of blood eosinophilia after 2 weeks of treatment and for the last 12 months of follow-up.

The diagnosis of EF in this case was based on the initial clinical symptoms and skin biopsy findings, together with peripheral hypereosinophilia.

The presence of visceral involvement first obliged us to exclude other systemic diseases such as systemic sclerosis and drug-induced lupus erythematosus, which do not usually present with hypereosinophilia $>1.5 \times 10^{9}$ and a clinical picture of EF. The patient did not produce antinuclear antibodies, had no clinical involvement of the fingers or facies, and denied Raynaud phenomenon. Visceral involvement and persistent hypereosinophilia at high levels also led us to consider toxic oil syndrome, eosinophilia-myalgia syndrome, and eosinophilic granulomatosis with polyangiitis (Churg-Strauss syndrome). The patient also denied having taken toxic adulterated rapeseed oil and had not been in contact with contaminated L-tryptophan. Eosinophilic granulomatosis with polyangiitis was ruled out, as the patient had no history of asthma or allergic rhinitis, the results for antinuclear antibodies and antineutrophil cytoplasmic antibodies were negative, and tissue biopsy did not reveal necrotizing vessel vasculitis or granulomatous inflammation.

The subsequent involvement of the peripheral and central nervous systems and the pulmonary and intestinal symptoms were interpreted as secondary to the endothelial cell damage and hypercoagulable state caused directly by uncontrolled eosinophilic infiltration and by the cytokine storm induced upon activation [3]. There are very few reports of the association between EF and isolated pulmonary [4], pleuropericardial [5], and renal involvement [6] or multiple mononeuropathy [7] resulting from secondary eosinophilic infiltration and tissue damage. The presence of visceral involvement with hypereosinophilia obliged us first to exclude other systemic diseases such as toxic oil syndrome, eosinophilia-myalgia syndrome, eosinophilic granulomatosis with polyangiitis (Churg-Strauss syndrome), and drug-induced or infectious diseases. We had to consider the possibility of hypereosinophilic syndrome (HES) accompanying the EF and therefore reviewed the current criteria for the different HES subtypes. Since the 2011 Working Conference on Eosinophil Disorders and Syndromes, HES has been divided into 3 subtypes: idiopathic HES, which has no underlying cause and no evidence of reactive or neoplastic/disorder; primary (neoplastic) HES, with underlying stem cell, myeloid, or eosinophilic neoplasm showing neoplastic (clonal) cells; and secondary (reactive) HES, with its lymphoid subvariant (with clonal $\mathrm{T}$ cells as the only potential cause) due to an underlying condition/disease in which eosinophils are considered nonclonal cells and end-organ damage is considered cytokinedriven [8]. Although it could be argued that the underlying HIV-1 infection could have played a role in reactive HES and the severity of organ involvement, the stable immune status and normal IgE levels recorded make this hypothesis unlikely. There is no evidence to date that HIV-1 infection by itself or the immune activation associated with HIV infection can trigger multiorgan damage in eosinophilic syndromes. The expert panel recognizes other conditions, including skin disorders, that can be accompanied by hypereosinophilia and that might rarely present with secondary organ damage attributable to tissue infiltration [8]. They conclude that if hypereosinophilia-induced organ damage occurs, the diagnosis changes from hypereosinophilia to HES regardless of whether hypereosinophilia can be ascribed to another underlying disease [8]. Although it might be argued that EF occurred as a cutaneous manifestation in the context of idiopathic HES, the temporary onset of symptoms and similar reports where EF precedes systemic symptoms incline us to believe that multiorgan involvement in the present case was secondary to reactive HES conditioned by initial EF.

Close follow-up to detect early onset of organ involvement or development of HES is desirable in all cases of EF. Early diagnosis can help improve prognosis and prevent severe multiorgan involvement.

\section{Funding}

The authors declare that no funding was received for this study.

\section{Conflicts of Interest}

The authors declare that they have no conflicts of interest.

\section{References}

1. Lakhanpal S, Ginsburg WW, Michet CJ, Doyle JA, Moore SB. Eosinophilic fasciitis: clinical spectrum and therapeutic response in 52 cases. Semin Arthritis Rheum. 1988;17:221-1. 
2. Lebeaux D, Frances C, Barete S, Wechsler B, Dubourg O, Renoux J, et al. Eosinophilic fasciitis (Shulman disease): new insights into the therapeutic management from a series of 34 patients. Rheumatology (Oxford). 2012;51:557-61.

3. Kita H. Eosinophils: multifaceted biologic properties and roles in health and disease. Immunol Rev. 2011;242:161-77.

4. Killen JW, Swift GL, White RJ. Eosinophilic fasciitis with pulmonary and pleural involvement. Postgrad Med J. 2000;76:36-7.

5. Rizzo S. Eosinophilic pleuropericarditis and fasciitis. A new case. Monaldi Arch Chest Dis. 2002;57:311-3.

6. Kirschstein M, Helmchen $U$, Jensen R, Kuster RM, Lehmann $H$. Kidney involvement in a 17-year-old boy with eosinophilic fasciitis. Clin Nephrol. 1999;52:183-7.

7. Pardal-Fernández JM, Sáez-Méndez L, Rodriguez-Vázquez M, Godes-Medrano B, Iñiguez-De Onzoño L. Mononeuritis múltiple y fascitis eosinofílica en una paciente con síndrome hipereosinofílico idiopático. Rev Neurol. 2012;54:100-4.

8. Valent $P$, Klion AD, Horny HP, Roufosse F, Gotlib J, Weller $P F$, et al. Contemporary consensus proposal on criteria and classification of eosinophilic disorders and related syndromes. J Allergy Clin Immunol. 2012;130:607-12.

I Manuscript received July 8, 2017; accepted for publication November 28, 2017.

Nina A Richarz

Hospital Universitari Germans Trias i Pujol Carretera de Canyet $s / n$ 08916 Badalona, Spain

E-mail: richarznina@gmail.com 